\title{
Neuronal Plasticity in the Nigrostriatal System of the Rat after Unilateral Removal of Vibrissae
}

\author{
J. P. Huston, S. Morgan, K. W. LANGe, AND H. SteineR ${ }^{1}$ \\ Institute of Psychology II, University of Dilsseldorf, Universitatsstrasse 1, \\ D-4000 Dusseldorf. Federal Republic of Germany
}

Received March 18, 1986

\begin{abstract}
The vibrissae of rats were shaved from one side of the face daily for 10 days. To see whether or not this treatment had an effect on crossed and uncrossed striatal afferent connections from the midbrain, the tract tracer horseradish peroxidase was applied to the caudate-putamen on day 11 . When the tracer was deposited on the side opposite the vibrissae removal, more labeled cells were found in the contralateral substantia nigra than when it was applied on the same side as the vibrissae removal, or placed in animals with intact vibrissae. Unilateral removal of vibrissae did not affect uptake of the tracer by the cells which give rise to the homolateral nigrostriatal projections. These changes in HRP labeling in the crossed projection from the substantia nigra were seen after 10 days of unilateral removal of the vibrissae; i.e., at a time when the animals have had opportunity to learn to compensate for vibrissotomy-induced behavioral asymmetries. (c) 1986 Academic Press, Inc.
\end{abstract}

\section{INTRODUCTION}

A temporal relationship has been found between plastic changes in crossed efferent connections of the substantia nigra (SN) and learning to compensate for lesion-induced sensorimotor asymmetries. Recovery from turning behavior, induced by unilateral lesions of the telencephalon or the $\mathrm{SN}$, was associated in time with an apparent increase in interhemispheric projections from the SN to the thalamus (Th) and caudate-putamen (CPU). The changes in these crossed projections were manifested by an increase in the

Abbreviations: CPU-caudate-putamen, HRP—horseradish peroxidase, RRA-retrorubral area, $\mathrm{SN}$-substantia nigra, Th-thalamus, VTA-ventral tegmental area.

${ }^{1}$ This work was supported by grant $\mathrm{Hu}$ 306/3-3 from the Deutsche Forschungsgemeinschaft. H. Steiner received support from the German-Swiss Academic Exchange Program (DAAD). 
number of neurons found in the $\mathrm{SN}$ of the undamaged hemisphere, retrogradely labeled by horseradish peroxidase (HRP) injected into the contralateral Th or CPU (8). Prevention of turning behavior, induced by unilateral destruction of the SN by 6-hydroxydopamine, suppressed both the behavioral recovery (i.e., the decrease in turning behavior) and the apparent increase in the projection from the undamaged SN to the contralateral Th (18), suggesting a relationship between those two phenomena.

Unilateral paralysis of the limbs and prevention of input from the vibrissae and eye, which also resulted in transient asymmetrical behavior, led to a similar neuronal asymmetry: when HRP was implanted in the Th on the side opposite the peripheral denervations, more labeled cells than normal were found in the contralateral SN (22). In the present experiment we examined whether or not removal of only the vibrissae from one side of the face for 10 days would result in plastic changes in the crossed nigrostriatal projection. We hypothesized that during a period of 10 days the animals would learn to compensate for many of the possible behavioral deficits (asymmetries) incured by unilateral removal of the vibrissae, the vibrissae being of paramount importance for many aspects of rat behavior (6). Based on the previous experimental results (22), we hypothesized that 10 days of unilateral vibrissae removal would be associated with an apparent increase in the crossed nigrostriatal projection arising from the $\mathrm{SN}$ ipsilateral to the side of vibrissae removal.

\section{METHODS}

Animals. Sixty-six male Wistar rats (150 to $190 \mathrm{~g})$ were housed in pairs with free access to food and water, and maintained on a 12-h light:12-h dark cycle. They were randomly assigned to one of three groups. Animals in group CUT SIDE and group INTACT SIDE had their vibrissae removed from one side of the face, and HRP was iontophoretically applied into the CPU in the hemisphere either on the same side as (group CUT SIDE) or the side opposite the vibrissae removal (group INTACT SIDE). The vibrissae of the animals in group NORMAL remained intact; these rats received HRP in either the right or left CPU.

Vibrissae Removal. The vibrissae of the two experimental groups (CUT SIDE and INTACT SIDE) were shaved with an electrical hair clipper daily for 10 consecutive days. The animals of the control group (NORMAL) were handled in the same manner as the experimental animals, except their vibrissae were not removed.

Surgery. On the 11th day each rat was anesthetized with equithesin (3 $\mathrm{ml} / \mathrm{kg}$, i.p.) and its head was placed in a David Kopf stereotaxic frame. A micropipet (inner diameter 20 to $25 \mu \mathrm{m}$ ), filled with a $4 \%$ solution of HRP 
(Boehringer Mannheim, Grade 1; in Tris- $\mathrm{HCl}$ buffer at $p \mathrm{H}$ 8.6) was lowered into the head of the caudate-putamen. The following coordinates were used for the tip of the pipet: $8.0 \mathrm{~mm}$ rostral and $4.7 \mathrm{~mm}$ dorsal to the interaural line, $3 \mathrm{~mm}$ lateral (with the incisor bar adjusted $2.5 \mathrm{~mm}$ below the interaural line). These coordinates corresponded to Konig and Klippel (13) coordinates: A 7890, V 0.2, L 2.5. After its insertion the pipet remained in place 5 min. Then, a continuous, 500-nA positive current was applied to the HRP solution via a silver wire for $20 \mathrm{~min}$. The current was produced by a DC constant current source. The reference electrode was connected to muscle tissue exposed at the back of the skull. The pipet was removed 5 min after the current had been discontinued. A negative current of $500 \mathrm{nA}$ was passed during insertion and removal of the pipet to prevent passive leakage of HRP from the tip.

Horseradish Peroxidase Histochemistry. Twenty-four hours after the application of HRP, the animals were anesthetized with an overdose of equithesin and perfused through the heart following the procedure described by Mesulam (17). The brains were removed from the skull and placed in sucrose phosphate buffer for about $24 \mathrm{~h}$ before being cut into $50-\mu \mathrm{m}$ frontal sections. The sections comprising the HRP deposition site and the $\mathrm{SN}$ were processed for HRP histochemistry using tetramethylbenzidine (Sigma) as chromogen (17). They were mounted on gelatinized slides, air-dried, and counterstained with neutral red.

Anatomical Analysis. The HRP deposition sites of all brains were checked for correct position within the CPU. Two experimenters independently examined all sections containing SN for HRP-labeled neurons. Labeled cells in the ipsilateral and contralateral SN, ventral tegmental area (VTA), and retrorubral area (RRA) were counted. The borders between the SN, VTA, and RRA were defined by criteria specified elsewhere (19).

In a recent study we found an imbalance between the hemispheres in the distribution of the crossed nigrostriatal projections, which was related to the direction of amphetamine-induced turning behavior. This anatomic asymmetry was strongest in the caudal part of the SN (19). Therefore, to see if an effect of unilateral vibrissae removal would also be restricted to part of the $\mathrm{SN}$, we looked at whether the contralaterally projecting neurons lay in the rostral, middle, or caudal parts of the SN [see (20) for the limits of these three parts].

\section{RESULTS}

The results are based on the anatomic data of 43 animals: 15 rats in grour NORMAL, 14 in group CUT SIDE, and 14 in group INTACT SIDE. There was only slight variability between the animals in placement of the pipet tip 

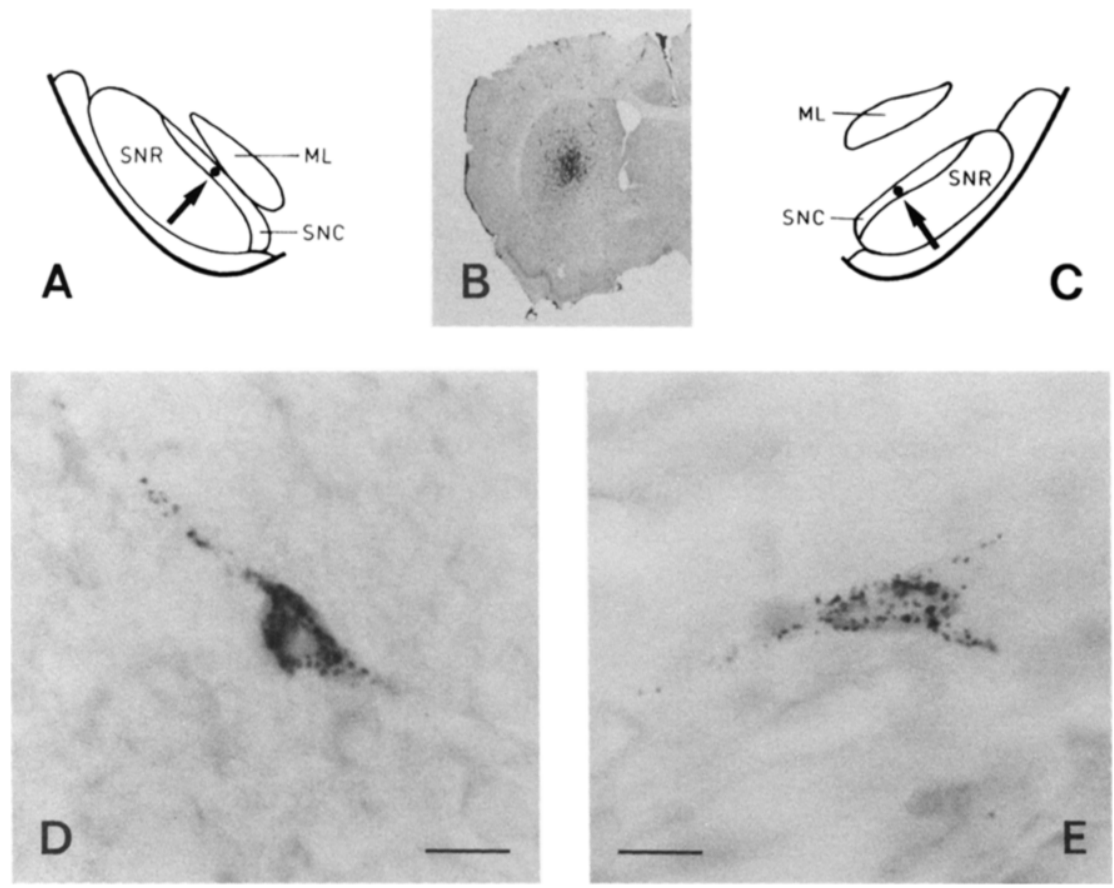

FIG. 1. B-photomicrograph of a horseradish peroxidase implantation site in the caudateputamen. D and E-photomicrographs of labeled cells found in the middle (D) and rostral (E) part of the contralateral substantia nigra. The positions of these cells are shown in diagrams A and $\mathrm{C}$, respectively. SNC-substantia nigra pars compacta, $\mathrm{SNR}$ - substantia nigra pars reticulata, ML-medial lemniscus. Bars $=10 \mu \mathrm{m}$.

and extent of spread of HRP within the CPU. Therefore, systematic differences between the groups in HRP deposition can be ruled out. A typical HRP deposition site is shown in Fig. 1, together with examples of labeled cells found in the contralateral SN.

The anatomical results are based on analysis of each available brain section from the $\mathrm{SN}$ ( 35 to 47 sections per SN). Ipsilateral to the HRP deposition site, 801 to 3497 HRP-labeled neurons were found in the SN, 15 to 215 neurons in the VTA, and 6 to 236 neurons in the RRA. The number of labeled neurons found contralateral to the HRP application site was 1 to 22 for the SN, 0 to 15 for the VTA, and 0 to 13 for the RRA.

The mean number of labeled neurons per section found in the SN, VTA, and RRA ipsilateral and contralateral to the side of HRP deposition are presented in Table 1. Mann-Whitney $U$ tests were carried out on these data (23). The exact one-tailed $P$ values calculated are also shown in Table 1. In 
accordance with our hypothesis, significance tests were made on the cell counts of the ipsilateral and contralateral SN. In order to take into account the use of multiple tests, the significance level $(\alpha=0.05)$ was adjusted for six dependent tests (to $\alpha^{\prime}=0.0083$ ) (16). These tests revealed an effect of unilateral vibrissae removal on the interhemispheric projection from the $\mathrm{SN}$ to the CPU. The animals in group INTACT SIDE (HRP placed in the CPU of the hemisphere on the side opposite vibrissae removal) had significantly more labeled neurons in the SN contralateral to the HRP deposition site than animals in group CUT SIDE (HRP deposited in the hemisphere on the same side as vibrissae removal; $P=0.0015$ ) and animals in group NORMAL (without vibrissae removal; $P=0.0050$ ). There were, however, no significant differences between the groups in the number of cells found in the ipsilateral $\mathrm{SN}$. Figure 2 depicts the mean numbers of labeled cells per section for the crossed and uncrossed nigrostriatal projections in the individual animals. Significance tests were not made on the post-hoc comparisons of the other regions. It is of interest to note, however, the low $P$ values of the VTA comparisons, suggesting a possible effect of the experimental treatment on the striatal afferent connections from this region. This finding might deserve closer scrutiny in future experiments. Figure 3 presents schematically the

\section{TABLE 1}

Number of HRP-Labeled Neurons per Section in the Substantia Nigra (SN), Ventral Tegmental Area (VTA), and Retrorubral Area (RRA) after Hemivibrissotomy in Rats ${ }^{a}$

\begin{tabular}{|c|c|c|c|c|c|c|}
\hline \multirow[b]{3}{*}{ Brain region } & \multirow{2}{*}{\multicolumn{3}{|c|}{$\begin{array}{c}\text { Mean number of labeled neurons } \\
\text { per section (SE) }\end{array}$}} & \multicolumn{3}{|c|}{$P^{b}$} \\
\hline & & & & \multirow{2}{*}{$\begin{array}{c}\text { NORMAL } \\
\text { versus } \\
\text { CUT }\end{array}$} & \multirow{2}{*}{$\begin{array}{c}\text { NORMAL } \\
\text { versus } \\
\text { INTACT }\end{array}$} & \multirow{2}{*}{$\begin{array}{c}\text { CUT } \\
\text { versus } \\
\text { INTACT }\end{array}$} \\
\hline & NORMAL & CUT SIDE & $\begin{array}{l}\text { INTACT } \\
\text { SIDE }\end{array}$ & & & \\
\hline \multicolumn{7}{|l|}{ Ipsilateral } \\
\hline SN & $61.52(5.91)$ & $55.15(4.87)$ & $55.10(3.18)$ & 0.1797 & 0.2291 & 0.4817 \\
\hline VTA & $1.41(0.23)$ & $1.49(0.30)$ & $1.96(0.24)$ & 0.4136 & 0.0368 & 0.0647 \\
\hline RRA & $7.45(1.19)$ & $6.77(0.97)$ & $7.56(0.79)$ & 0.3717 & 0.2425 & 0.3826 \\
\hline \multicolumn{7}{|l|}{ Contralateral } \\
\hline $\mathbf{S N}$ & $0.16(0.02)$ & $0.15(0.02)$ & $0.29(0.04)$ & 0.4393 & $0.0050^{*}$ & $0.0015^{*}$ \\
\hline VTA & $0.07(0.02)$ & $0.10(0.03)$ & $0.12(0.03)$ & 0.2917 & 0.0628 & 0.2167 \\
\hline RRA & $0.20(0.04)$ & $0.19(0.06)$ & $0.34(0.10)$ & 0.2674 & 0.2154 & 0.1045 \\
\hline
\end{tabular}

${ }^{a}$ Cell counts were from the side ipsilateral or contralateral to the HRP deposition in the striatum of animals without vibrissae removal (NORMAL), with vibrissae cut on side of HRP deposition (CUT SIDE) and with vibrissae intact on side of HRP deposition (INTACT SIDE).

${ }^{b}$ One-tailed $P$-values calculated with Mann-Whitney $U$ tests.

* Significant difference based on adjusted level of significance $\left(\alpha^{\prime}=0.0083\right)$. 


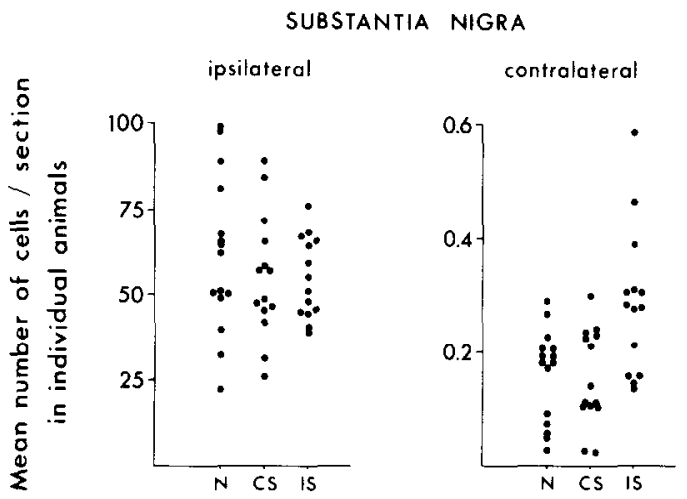

FIG. 2. The mean number of labeled neurons per section found in the substantia nigra ipsilateral and contralateral to the horseradish peroxidase (HRP) application. Each dot represents the result from one animal. N-group NORMAL, CS-group CUT SIDE, with HRP applied to the caudate-putamen on the same side as the vibrissae removal, IS-group INTACT SIDE, with HRP applied on the side opposite the vibrissae removal.

effects of unilateral vibrissae removal on the crossed and uncrossed nigrostriatal projections.

The rostrocaudal distributions of the contralaterally projecting SN neurons in the three groups are shown in Fig. 4. The mean number of labeled neurons per section for the rostral, middle, and caudal parts of the SN contralateral to the HRP deposit are shown. Post-hoc analysis showed that animals of group INTACT SIDE had more labeled cells only in the rostral part (versus group CUT SIDE, $P=0.0003$; versus group NORMAL, $P=0.0022$ )

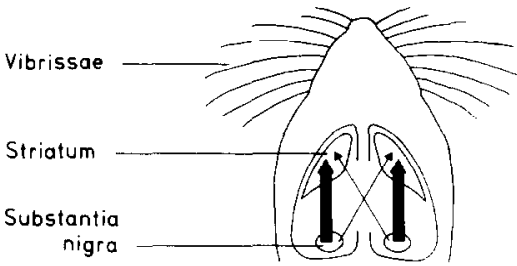

VIBRISSAE INTACT

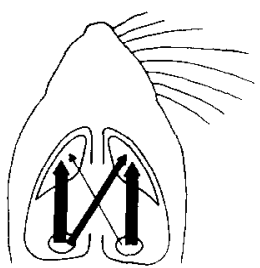

UNILATERAL

VIBRISSAE REMOVAL

FIG. 3. Schematic summary of changes in nigrostriatal connections after unilateral vibrissae removal. 


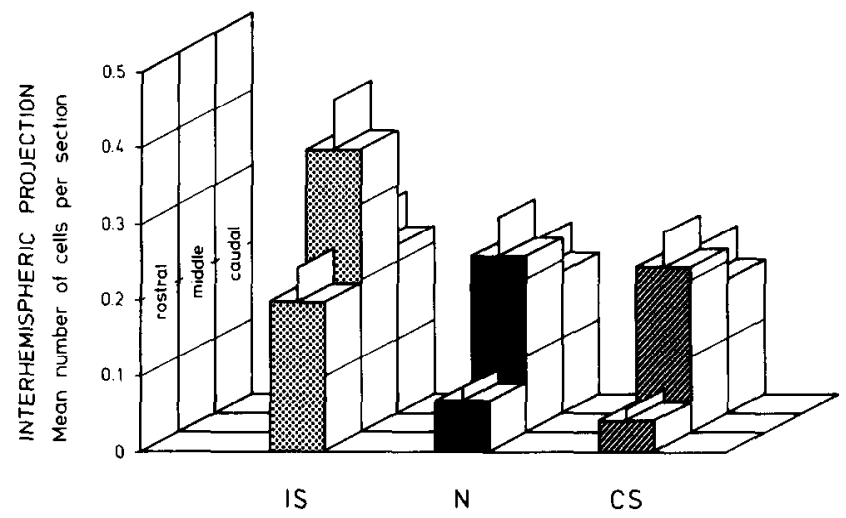

FIG. 4. The mean (+SE) number of labeled cells per section found in the rostral, middle, and caudal parts of the substantia nigra contralateral to the caudate-putamen (CPU) into which HRP was deposited. IS-group INTACT SIDE, HRP applied to the CPU on the side opposite the vibrissae removal. N-group NORMAL, vibrissae intact. CS-group CUT SIDE, HRP applied to the CPU on the same side as the vibrissae removal.

and the middle part (versus group CUT SIDE, $P=0.0296$; versus group NORMAL, $P=0.0301$ ).

\section{DISCUSSION}

In this experiment we found that unilateral removal of the vibrissae for 10 days led to changes in HRP labeling in the crossed nigrostriatal projection. When HRP was applied to the CPU on the side opposite the vibrissae removal, more labeled cells were found in the contralateral SN than in normal control animals, or in animals which received HRP in the CPU on the side of vibrissae removal. This experimentally induced anatomic asymmetry was confined to the crossed nigrostriatal projection; the numbers of labeled cells in the ipsilateral SN did not differ among the three groups. Thus, it is unlikely that the finding was due to some adventitious difference between groups in the amount of applied HRP.

The change in uptake of HRP by the cells which give rise to the crossed nigrostriatal projection could be attributable to several different effects. It has been shown that uptake and retrograde transport of HRP are related to the activity of synapses and transmitter release $(5,14,21)$, as well as the number of synapses present in a HRP deposition site (11). Thus, the change in cell labeling found here could reflect alterations in synaptic activity and/or number of terminals.

Recently, we found the direction of amphetamine-induced circling to be also related to an asymmetrical distribution of the interhemispheric nigro- 
striatal projections. This anatomic imbalance was, however, predominantly seen in the caudal part of the SN (19). In contrast, the results of the present experiment showed unilateral vibrissae removal to mainly affect neurons that lay in the rostral and middle parts of the $\mathrm{SN}$. Further experiments are mandatory to determine the basis of these findings.

Extensive experimentation has demonstrated that vibrissae removal in neonates results in profound anatomic alterations within the four major synaptic stations of the trigeminal system $(1,2,10,12)$. Our study shows changes in a system other than the trigeminal one. Moreover, although removal of the vibrissae in the adult mouse is associated with a reduction in neural activity in corresponding barrels of the SmI cortex (4), other central effects of vibrissae removal, as far as we know, have not been reported for the adult animal. Thus, our results are additionally interesting as they demonstrate plastic changes, in response to vibrissae removal, in the adult animal.

We demonstrated elsewhere a relationship between an asymmetry in sensorimotor responsiveness of the vibrissae region and the direction of turning elicited either by unilateral damage to the $\mathrm{SN}(9)$ or by unilateral injection of GABA agonists $(9,26)$ or neuropeptides $(25,26)$ into the SN. Furthermore, Szechtman (24) showed that apomorphine induced turning in normal rats that had an asymmetry in sensory input, induced by bandaging the head on one side. Moreover, it was shown that neurons in the $\mathrm{SN}$ will respond to sensory stimuli, including stimuli presented to the face $(3,7)$. Together, these findings argue for a functional relationship between activity in the nigrostriato-nigral system and sensory input from the face, including the vibrissae. We suggested that the $\mathrm{SN}$ is part of a system that determines the input, and/or the response to the input from the vibrissae, by influencing the sensorimotor field to tactile stimulation (9) [see also Lidsky et al. (15) for a similar theory]. Further evidence for such a relationship is provided by the findings of the present study, in that unilateral removal of the vibrissae results in physiologic changes in the crossed nigrostriatal projection.

We earlier found changes in crossed nigrothalamic and nigrostriatal projections that appear in a time-dependent manner correlated with recovery from brain lesion-induced behavioral asymmetries ( 8 ), and, therefore, postulated a relationship between such changes and learning to compensate for lesion-induced asymmetries. In the present study the change in number of labeled cells was measured after 10 days of vibrissac removal, when the animals presumably had had sufficient time to learn to adapt to the asymmetry in sensory input from the vibrissae. It remains to be determined, first, what kinds of learning take place during 10 days of hemivibrissotomy, and, second, whether or not such presumed learning is linked to the central anatomic changes we described above. 


\section{REFERENCES}

1. Belford, G. R., AND H. P. Killackey. 1979. Vibrissae representation in subcortical trigeminal centers of the neonatal rat. J. Comp. Neurol. 183: 305-322.

2. BELFORD, G. R., AND H. P. KILLACKEY. 1979. The development of vibrissae representation in subcortical trigeminal centers of the neonatal rat. J. Comp. Neurol. 188: 63-74.

3. Chiodo, L. A., S. M. ANTElman, A. R. CaGgiula, AND C. G. LineberRy. 1980. Sensory stimuli alter the discharge rate of dopamine (DA) neurons: evidence for two functional types of DA cells in the substantia nigra. Brain Res. 189: 544-549.

4. DURHAM, D., AND T. A. WOOLSEY. 1978. Acute whisker removal reduces neuronal activity in barrels of mouse SmI cortex. J. Comp. Neurol. 178: 629-644.

5. EISENMAN, J. S., AND E. C. AZMITIA. 1982. Physiological stimulation enhances HRP marking of salivary neurons in rats. Brain Res. Bull. 8: 73-78.

6. Gustafson, J. W., AND S. L. Felbain-Keramidas. 1977. Behavioral and neural approaches to the function of the mystacial vibrissae. Psychol. Bull. 84: 477-488.

7. HARPER, J. A., T. LABUSZEWSKI, AND T. I. LIDSKY. 1979. Substantia nigra unit responses to trigeminal sensory stimulation. Exp. Neurol. 65: 462-470.

8. Huston, J. P., S. MORGAN, AND H. STEINER. 1985. Behavioral correlates of plasticity in substantia nigra efferents. Pages 383-395 in B. E. WILL, P. SCHMITT, AND J. C. DALRYMPLE-ALFORD, Eds., Brain Plasticity, Learning and Memory. Plenum, New York.

9. Huston, J. P., B. Nef, G. PAPAdOPOulos, AND H. WelzL. 1980. Activation and lateralization of sensorimotor field for perioral biting reflex by intranigral GABA agonist and by systemic apomorphine in the rat. Brain Res. Bull. 5: 745-749.

10. JEANMONOD, D., F. L. RICE, AND H. VAN DER LOOS. 1981. Mouse somatosensory cortex: alterations in the barrelfield following receptor injury at different early postnatal ages. Neuroscience 6: 1503-1535.

11. JONES, E. G. 1975. Possible determinants of the degree of retrograde neuronal labeling with horseradish peroxidase. Brain Res. 85: 249-253.

12. KILlACKEY, H. P., AND G. R. BELFORD. 1979. The formation of afferent patterns in the somatosensory cortex of the neonatal rat. J. Comp. Neurol. 183: 285-304.

13. KöNIG, J. F. R., AND R. A. KLIPPEL. 1963. The Rat Brain: A Stereotaxic Atlas. Krieger, New York.

14. KRISTENSSON, K. 1978. Retrograde transport of macromolecules in axons. Annu. Rev. Pharmacol. Toxicol. 18: 97-110.

15. LIDSKY, T. I., C. MANETTO, AND J. S. SCHNEIDER. 1985. A consideration of sensory factors involved in motor functions of the basal ganglia. Brain Res. Rev. 9: 133-146.

16. LUNNEY, G. H. 1969. Individual size for multiple t-tests. Am. Ed. Res. J. 6: 701-703.

17. MESUlaM, M.-M. 1982. Principles of horseradish peroxidase neurohistochemistry and their applications for tracing neural pathways-axonal transport, enzyme histochemistry and light microscopic analysis. Pages 1-151 in M.-M. Mesulam, Ed., Tracing Neural Connections with Horseradish Peroxidase. Wiley, New York.

18. Morgan, S., J. P. Huston, AND M. PRITzEl. 1983. Effects of reducing sensory-motor feedback on the appearance of crossed nigro-thalamic projections and recovery from turning induced by unilateral substantia nigra lesions. Brain Res. Bull. 11: 721-727.

19. MoRgan, S., H. STEINER, AND J. P. HuSTON. 1985. Relationship between interhemispheric nigrostriatal projections and the direction of rotational behavior induced by amphetamine. Exp. Neurol. 90: 149-161.

20. Morgan, S., H. Steiner, C. Rosenkranz, and J. P. Huston. 1986. Dissociation of crossed and uncrossed nigrostriatal projections with respect to site of origin in the rat. Neuroscience 17, 609-614. 
21. Nishino, H., T. Ono, K. SaSaki, A. Nishino, and K. MuRamoto. 1979. Retrograde transport of horseradish peroxidase in sciatic nerve of rats and dystrophy mice. Neurosci. Lett. 14: 1-6.

22. Sabel, B. A., M. Pritzel, S. MoRgan, and J. P. Huston. 1984. Interhemispheric nigrothalamic projections and behavioral recovery following turning behavior induced by unilateral peripheral sensory and motor restriction. Exp. Neurol. 83: 49-61.

23. SIEGEL, S. 1956. Nonparametric Statistics for the Behavioral Sciences. McGraw-Hill, New York.

24. SzEChTMAN, H. 1983. Peripheral sensory input directs apomorphine-induced circling in rats. Brain Res. 264: 332-335.

25. WELZL, H., H. G. FLACK, AND J. P. HUSTON. 1982. Contraversive circling and facilitation of the perioral biting reflex by injection of substance $\mathbf{P}$ or D-ala ${ }^{2}$-met-enkephalinamide into the substantia nigra. Behav. Neur. Biol. 34: 104-108.

26. WelzL, H., R. Schwarting, J. Kulajta, and J. P. Huston. 1984. Perioral biting reflex and turning after intranigral injection of a GABA- or metenkephalin-agonist: role of the thalamus and superior colliculus. Exp. Brain Res. 55: 438-444. 